Proceedings of the 2011 Winter Simulation Conference

S. Jain, R.R. Creasey, J. Himmelspach, K.P. White, and M. Fu, eds.

\title{
OPERATIONS MODELING AND ANALYSIS OF AN UNDERGROUND COAL MINE
}

\author{
Kanna Miwa \\ Nagoya Gakuin University \\ Faculty of Commerce \\ 1-25 Atsutanishimachi, \\ Atsuta-ku, Nagoya, Aichi, \\ 456-8612, JAPAN
}

\author{
Soemon Takakuwa \\ Nagoya University \\ Graduate School of Economics and Business Ad- \\ ministration, \\ Furo-cho, Chikusa-ku, Nagoya, Aichi, \\ 464-8601, JAPAN
}

\begin{abstract}
In general, it is quite difficult to describe and model operations and conveyance systems precisely in underground coal mines because of geological components, poor visibility, unreliable installed facilities, and difficult work conditions. In this study, a simulation model of an operations and materials handling system for an underground coal mine was built to investigate the relationship between the coal output and materials handling systems, which includes specifications for the facilities and the buffer space for the storage bin underground. It was found that it is possible to find the bottleneck of a conveyance system to determine more efficient mining and conveyance methods by performing a simulation.
\end{abstract}

\section{INTRODUCTION}

Underground mining is a dangerous industry because of geological disasters, poor visibility, workplace hazards, and difficult work conditions. The mining industry is aware of the need to improve productivity continually. This improvement can be achieved by introducing improved and more efficient mining methods, optimizing production for a given set of resources, and improving mine design and equipment selection. Site mining engineers face decisions in design, planning, production, development, and operations, and the full implications of each choice are neither clear nor quantified. The benefits to a mine with a formal decision support model are significant (Hoare and Willis 1992). The problems facing the industry are growing in both size and complexity. Production is time dependent, and work practices not only reduce production but also enforce inefficient use of expensive capital equipment. Simulation can be used to aid management in making decisions related to daily production and capital expenditure. Underground mines often face uncertainty in production planning associated with diverse sources such as grade distribution, ground conditions, equipment reliability, infrastructure needs and extraction method performance. Despite their best planning efforts, such operating uncertainty needs to be counter-balanced by integrating a contingency plan to enhance flexibility in mine plants (Kazakidis and Scoble 2003).

The development, demonstration and implementation of a virtual reality simulation have been described for coal mining industries (Stothard, Galvin, and Fowler 2004). From the standpoint of occupational health and safety management, virtual reality simulations were developed to provide more effective education, training and assessment. Virtual reality simulations enable trainees to experience a range of real situations that they may otherwise not encounter prior to a critical event (Zhao, Lucas, and Thabet 2009; Zhou and Guo 2011). Modeling and simulation of particle size distribution and exploratory tools for real mining equipment operator activities have been studied (Harper and Harper 1998; Larinkari, Kaartinen, and Miettunen 2004).

System dynamics models have been introduced to build a model of underground coal mines (Coyle 1985). Regarding open pit mining, LP-based disaggregation approaches to solve production scheduling 
problem have been proposed (Boland et al. 2009). In addition, the use of operation process simulation for Six Sigma Projects has been introduced to illustrate the process to define, measure, analyze and improve the current process (Chinbat and Takakuwa 2008).

In this study, a simulation model was constructed and used to examine the performance of an underground coal mine. The conveyance system from the longwall mining site to ground facilities comprises scraper chain conveyors, a storage bin, and the main-shaft skips. The relationship between mining speed and the velocity of the main-shaft skips was examined in conjunction with the inventory of the coal storage bin underground.

\section{UNDERGROUND COAL MINING AND OPERATIONS}

Technological advancements have made coal mining more productive than it has ever been. To keep up with technology and to extract coal as efficiently as possible, modern mining personnel must be highly skilled and well-trained in the use of complex, state-of-the-art instruments and equipment. Coal is mined by two methods: surface, or open pit, mining and underground, or deep, mining. There are two main methods of underground mining: room-and-pillar and longwall mining. Self-advancing, hydraulicallypowered supports temporarily hold up the roof while coal is extracted (Japan Coal Energy Center 2010).

In this study, underground coal mining with the longwall shearer is examined. An overview of the coal mine is shown in Figure 1. The longwall shearer is a sophisticated machine with a rotating drum that moves mechanically back and forth across a wide coal seam. The loosened coal falls on to a pan line that takes the coal to the conveyor belt for removal from the work area. Then, the coal is transferred to the storage bin by the conveyor. Finally, the coal is transported up to the ground by the main-shaft skip.

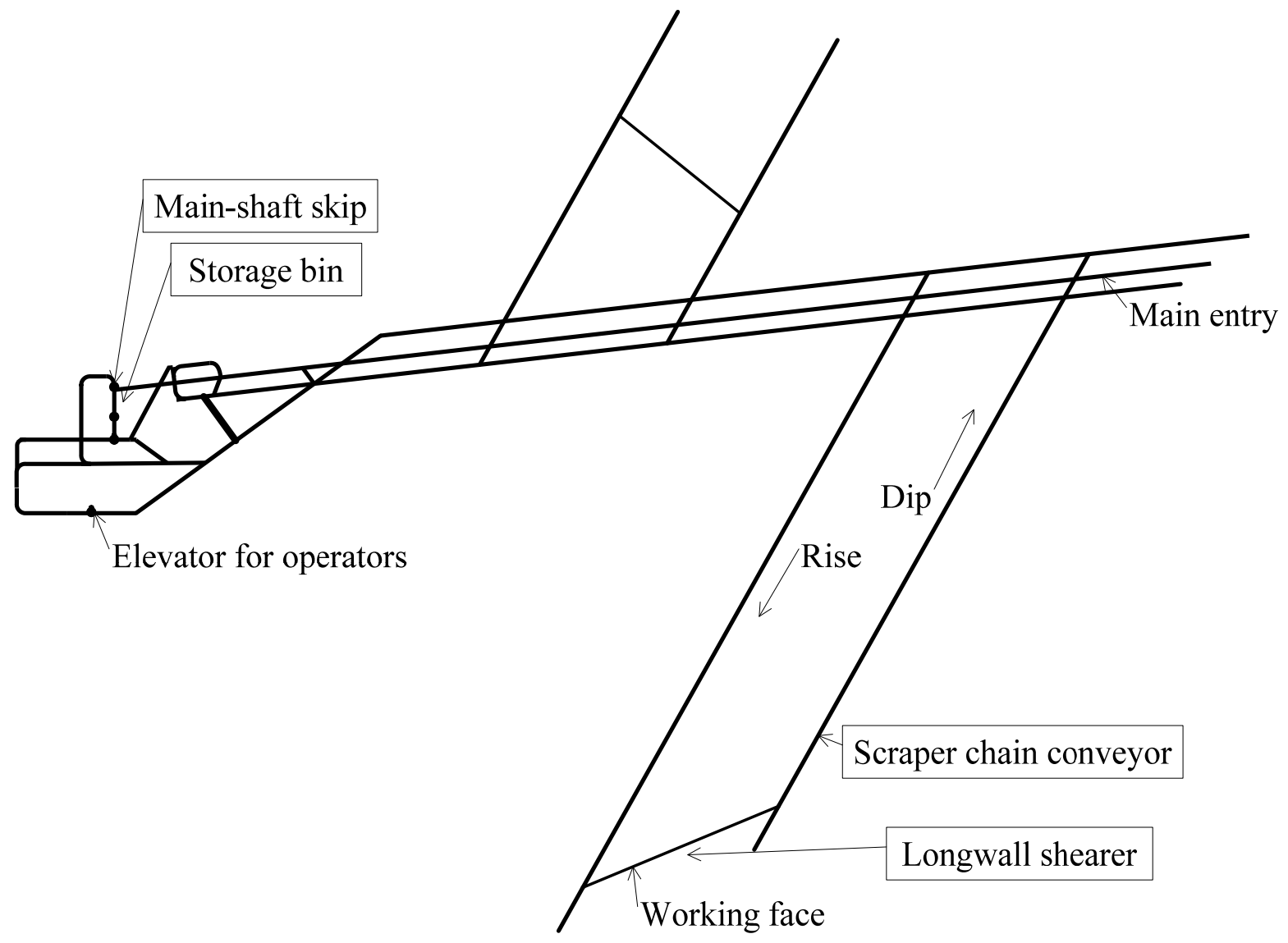

Figure 1: Overview of coal mining 


\section{Miwa and Takakuwa}

A survey shows that the longwall-utilization rate is 68 percent out of the scheduled availability, the shift-off is 7 percent, and the down time is 25 percent, as shown in Figure 2 (a). Furthermore, 61 percent of the longwall-utilization involves the time needed for cutting operations, and 39 percent is operational delay, as shown in Figure 2 (b). The associated operational delay includes a longwall move, mining delay, collapse, and an escape of gas, for example.

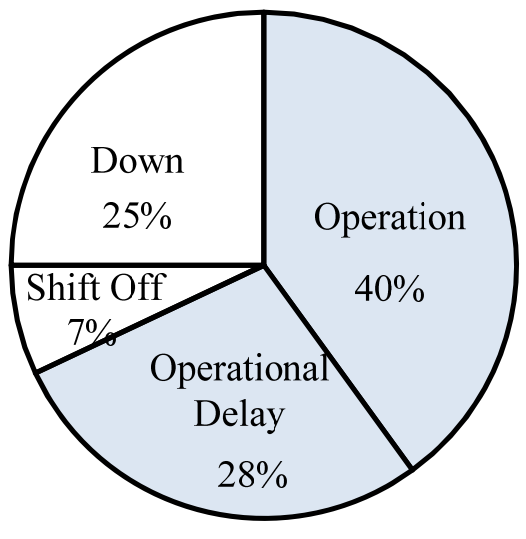

(a) Scheduled Availability

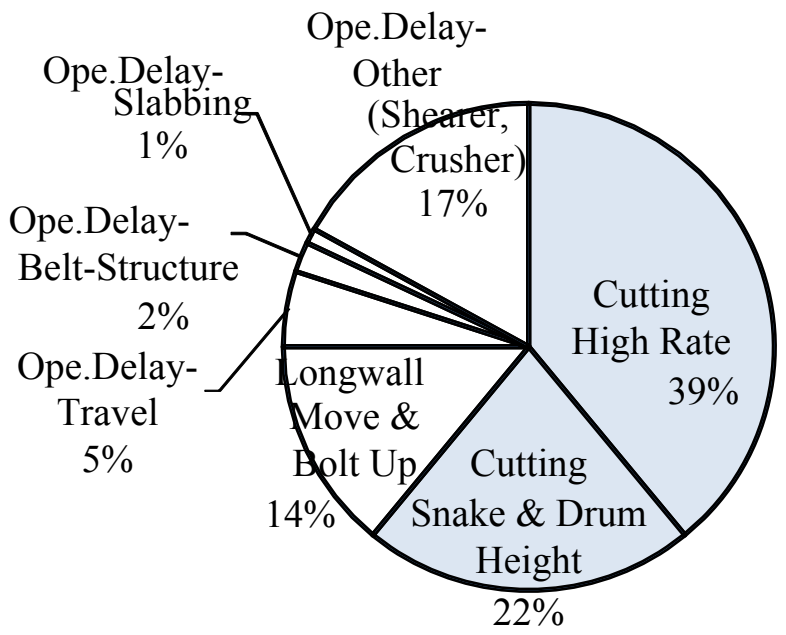

(b) Longwall Utilization

Figure 2: Scheduled availability and longwall utilization (Japan Coal Energy Center 2010)

\section{3}

\section{DATA AND SIMULATION MODEL}

\subsection{Simulation model}

These simulation programs were written in Arena (Kelton, Sadowski, and Swets 2010). Figure 3 shows the major flow of the operations in the simulation model. The proposed model is composed of two major logical subsystems: worker logic and mining logic. In worker logic, the operators were assigned to specific tasks. At the beginning of the designated work shift, the operators moved in a group to the assigned positions in the underground mining site, and they performed operations for the predetermined working time. At the end of the work shift, they finished their work and returned to ground. Each work shift was 6 hours.

In mining logic, however, coal was identified using the available data. Coal was excavated based on the production capacity of the installed longwall shearers whenever all operators of the group were at their posts and the machines were available. After performing excavation, the coal was transferred by the scraper chain conveyor to the storage bin area underground to await the main-shaft skip. Sixteen tons of coal were loaded into one of the main-shaft skips and then transferred to ground. Finally, the conveyed coals were unloaded from the main-shaft skip.

\subsection{Parameters}

The simulation model consists of several parameters. Table 1 shows the tasks performed by the operators of a group. The 33 operators are classified into 12 categories. In addition, Table 2 summarizes the list of parameters to be used for executing simulation. Based on our investigation into the underground coal mine and interviews with the managers of the mining company, the equipment capabilities were identified. The machine failure rates and operator travel times were estimated based on investigation and the drift map under the ground. 


\section{Miwa and Takakuwa}
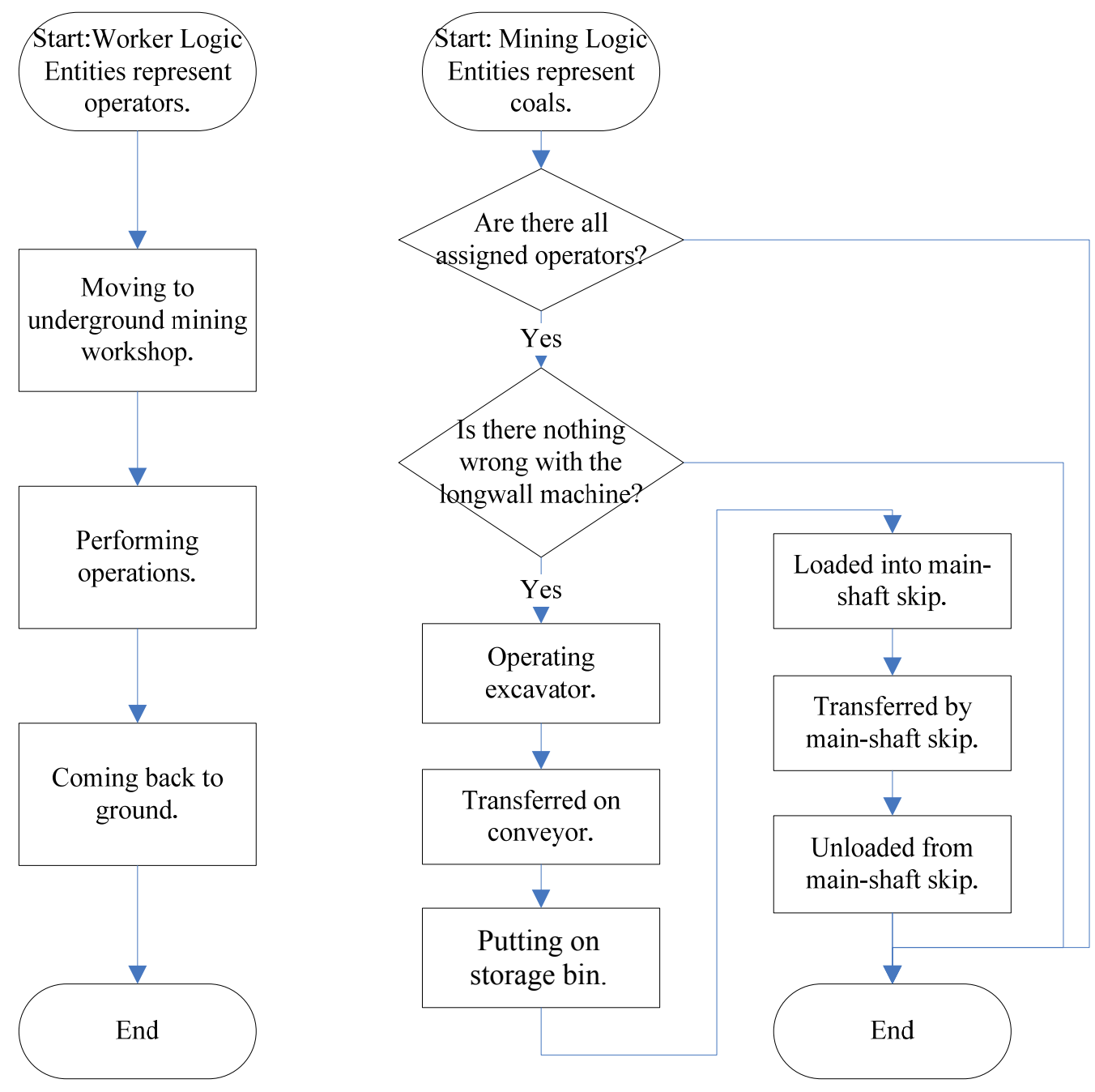

Figure 3: Flow of simulation program

Table 1: Work descriptions

\begin{tabular}{c|l|l|c}
\hline $\begin{array}{c}\text { Work } \\
\text { No. }\end{array}$ & \multicolumn{1}{|c|}{ Work Title } & \multicolumn{1}{|c}{ Duty } & $\begin{array}{c}\text { Number of } \\
\text { Operators }\end{array}$ \\
\hline 1 & mining safety monitor & management of the whole team & 3 \\
2 & coal mining machine drivers & control the coal mining machine & 2 \\
3 & scraper conveyor drivers & control the scraper conveyor & 2 \\
4 & hydraulic support A & use hydraul ic support to avoid roof falling & 4 \\
5 & hydraulic support B & assistant with hydraulic A & 6 \\
6 & material transporter & transportation of material & 8 \\
7 & belt driver & lonveyor's utilization and maintenance & 2 \\
8 & pumping station deriver & unsure/emergency & 1 \\
9 & electricity station driver & unsure/emergency & 1 \\
10 & water pump driver & unsure/emergency & 1 \\
11 & maintenance staff & maintain of machines & 2 \\
12 & controller & monitor the performance of equipments & 1 \\
\hline
\end{tabular}


Miwa and Takakuwa

Table 2: List of coal mining operation parameters

\begin{tabular}{l|c}
\hline Storage Bin & 2 (units) \\
\hline Main-shaft skip & $6(\mathrm{~m} / \mathrm{sec})$ \\
Velocity of main-shift skip & $360(\mathrm{~m})$ \\
Distance & $10(\mathrm{sec})$ \\
Loading Time, Unloading Time & $3.15(\mathrm{~m} / \mathrm{sec})$ \\
\hline Scraper Chain Conveyor & $170(\mathrm{~kg} / \mathrm{m})$ \\
\hline Velocity of scraper chain conveyor & $3000(\mathrm{~m})$ \\
Cell size & $16(\mathrm{tons} / \mathrm{min})$ \\
Length & \\
\hline Mining Machine & $\mathrm{UNIF}(24)(\mathrm{min})$ \\
\hline Excavation Quantity & $\mathrm{UNIF}(15)(\mathrm{min})$ \\
\hline Failure & \\
\hline UpTime & \\
DownTime & TRIA $(0.4,0.5,0.8)(\mathrm{hour})$ \\
\hline Operator & $8: 00-14: 00$ \\
\hline TravelTime & $14: 00-20: 00$ \\
Shift & $20: 00-2: 00$ \\
& $2: 00-8: 00$ \\
\hline
\end{tabular}

$\mathrm{UNIF}=$ Uniform, TRIA=Triangular

\subsection{Performance Measures}

The conveyance capacity of the main-shaft skips was identified as the bottleneck in the materials handling system. The expected capacity of the conveyed coals by the main-shaft skip in one day $(E C)$ was given by,

where

$$
E C=\frac{43200 n w}{d / v+l}
$$

$d(\mathrm{~m})$ : distance in height of main-shaft skip,

$l$ (sec): loading/unloading time,

$n$ (units): number of main-shaft skips,

$v(\mathrm{~m} / \mathrm{sec})$ : velocity of the main-shaft skip,

$w$ (tons): load weight of coals conveyed once by the main-shaft skip.

This study employs a discrete event simulation technique. The primary performance measures considered in this study are as follows:

- The average inventory in storage bin (tons).

- The maximum inventory in storage bin (tons).

- The output of coals mined in one day (tons/day).

- Average weight of coals in a unit space of the scraper chain conveyor (tons $/ \mathrm{m}$ ). 


\section{SIMULATION ANALYSIS}

\subsection{Scenarios}

Simulation technology provides a very powerful way to move from an "as-is" system to an ultimate "tobe" system. An "as-is" system accurately captures the behavior of the original system and then hypothetically changes the system until the best scenario is identified. By conducting a "what-if" analysis, the simulation analysis should be able to discover a future determined without implementing the technology (Profozich 1998). In the study, the coal output using excavation is 16 tons $/ \mathrm{min}$. As they improve productivity by enhancing the longwall shearer at the working face and adopting improved equipment, the following matters must be investigated in terms of materials handling:

- Sufficient buffer size at the storage bin.

- Recommended velocity of the main-shaft skip.

- Allowable weight of coals on a unit space of scraper chain conveyor.

Table 3 shows the properties to be examined through simulation. Simulation experiments were executed by repeating the experiment 30 times and forming a 95\% confidence interval for the expected average inventory and the expected maximum inventory in the storage bin and the expected quantity of conveyed coals. Let the ratio, $k$, of the baseline productivity be 1.0 when the quantity of excavated coals is 16 tons per minute. Thus, the ratio for the quantity of excavated coals was set between 1.0 and 2.0 at intervals of 0.2. In addition, the velocity of the main-shaft skip was set between 3 and 9.5 at intervals of 0.5 $(\mathrm{m} / \mathrm{s})$. Therefore, there were a total number of 151 scenarios.

Table 3: Scenario data

\begin{tabular}{|c|c|c|c|}
\hline \multirow[b]{2}{*}{ Scenarios Name } & \multicolumn{3}{|c|}{ Scenario Properties } \\
\hline & Number of Replications & $\begin{array}{c}\text { Productivity } \\
(16(\text { ton } / \mathrm{min})=1.0)\end{array}$ & $\begin{array}{c}\text { Velocity of Main-Shaft } \\
\text { Skip }(\mathrm{m} / \mathrm{s})\end{array}$ \\
\hline Baseline Case 01 & \multirow{4}{*}{30} & \multirow{4}{*}{1.0} & 3.0 \\
\hline Baseline Case 02 & & & 3.5 \\
\hline omitted & & & omitted \\
\hline Baseline Case 14 & & & 9.5 \\
\hline Scenario 0101 & \multirow{4}{*}{30} & \multirow{4}{*}{1.2} & 3.0 \\
\hline Scenario 01_02 & & & 3.5 \\
\hline omitted & & & omitted \\
\hline Scenario $01 \quad 14$ & & & 9.5 \\
\hline omitted & omitted & omitted & omitted \\
\hline Scenario 05_01 & \multirow{4}{*}{30} & \multirow{4}{*}{2.0} & 3.0 \\
\hline Scenario 05_02 & & & 3.5 \\
\hline omitted & & & omitted \\
\hline Scenario $05 \quad 14$ & & & 9.5 \\
\hline
\end{tabular}




\subsection{Simulation Results}

The animation model was constructed, as shown in Figure 4. The entity picture was set for each type of operator and coal, and the location of the coal was identified easily by viewing the animation of the simulation model.

Important insight was obtained by performing a simulation. Figure 5 shows the quantity of conveyed coals at the designated velocity of the mine-shaft skip. In this figure, the expected capacity of conveyed coals was obtained using equation (1). It was found that the capacity of the mine-shaft skip was the bottleneck of the entire conveyance system. Figure 6 shows the 95 percent confidence interval for the average inventory in the storage bin in each scenario. In addition, Figure 7 shows the 95 percent confidence interval for the maximum inventory in the storage bin in each scenario. Figure 8 shows the weight of coal in a unit space on the scraper chain conveyor. The amount of coal output was restricted by the conveyance capacity of the main-shaft skips. For example, when the productivity was set to $k=1$ in Figure 5, even if the velocity of the mine-shaft skip was $3 \mathrm{~m} / \mathrm{sec}$, all of the output coal underground was transferred on the ground. Then, the expected maximum inventory in storage bin was 1679 tons. The weight of coal in a unit space on the scraper chain conveyor would be 235 tons.

Next, when the productivity was set to $k=2$ in Figure 5, all coal was transferred on the ground by the mine-shaft skips at a velocity of $6 \mathrm{~m} / \mathrm{sec}$. However, the buffer area required to store the maximum inventory in the storage bin reached to 4049 tons. If the same storage bin as that for $k=1$ were used, they could speed up the mine-shaft skip to $9.5 \mathrm{~m} / \mathrm{sec}$. The weight of coal on a unit space of the scraper chain conveyor would be 506 tons.

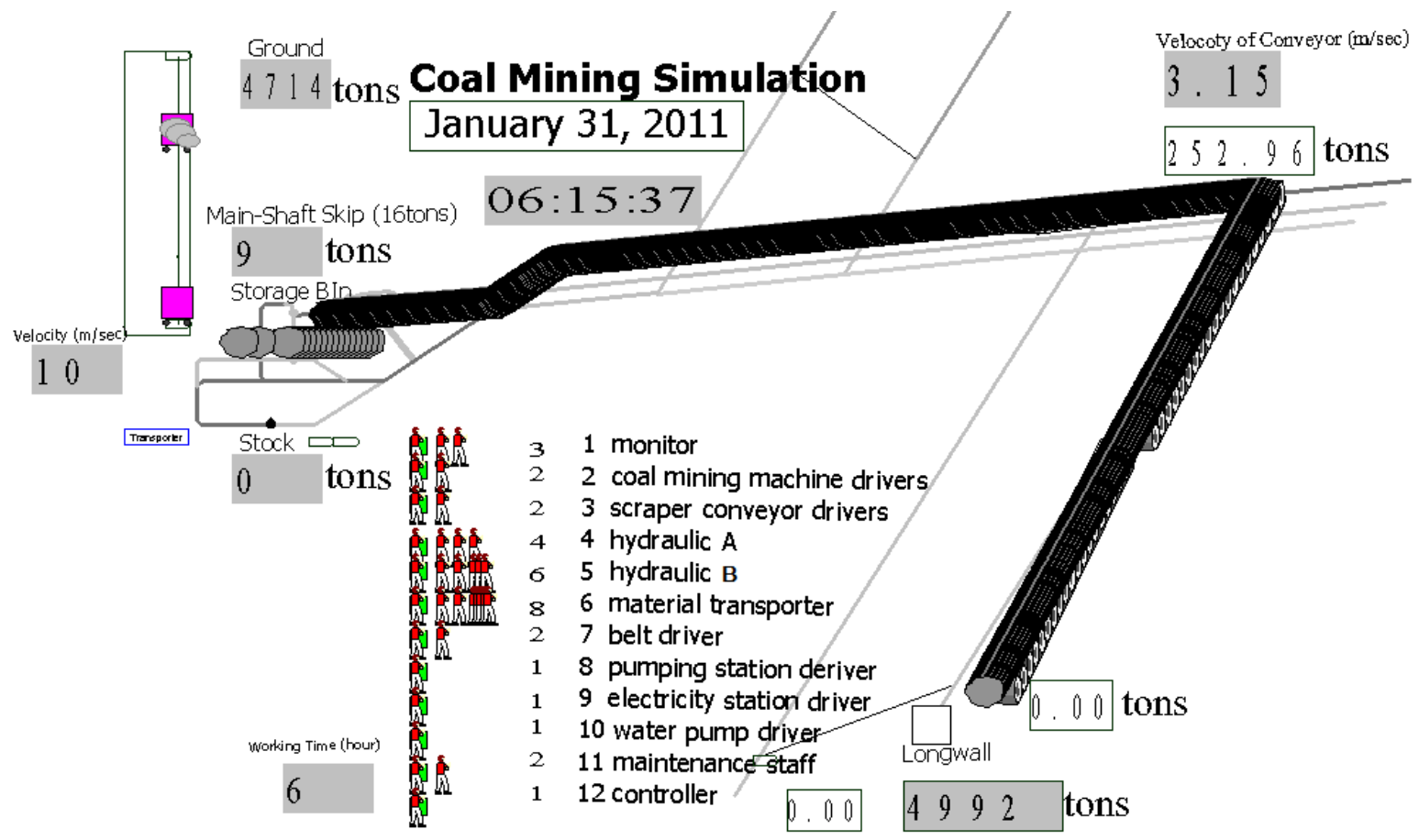

Figure 4: Model animation 


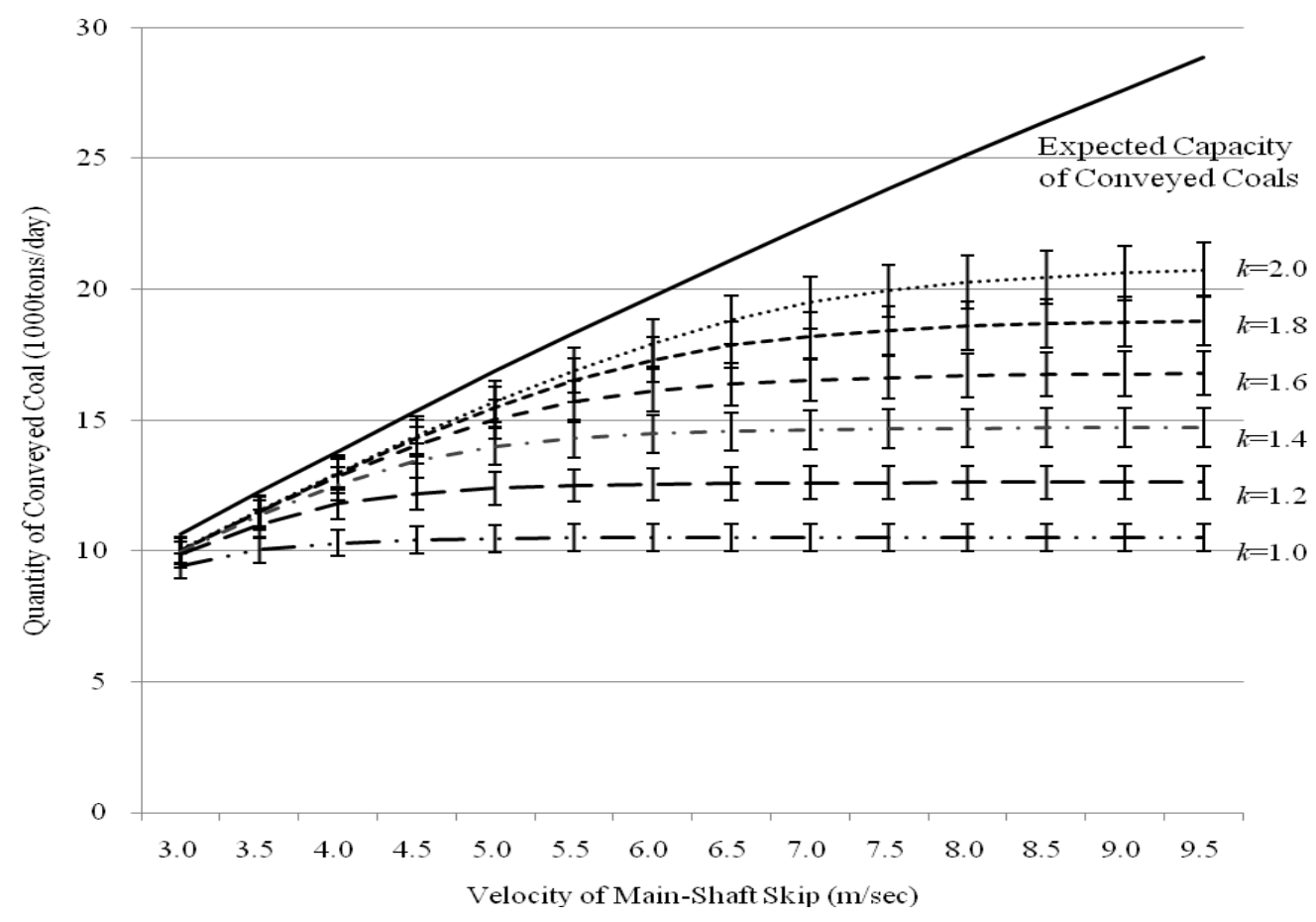

Figure 5: Quantity of conveyed coal at a designated mine-shaft skip velocity

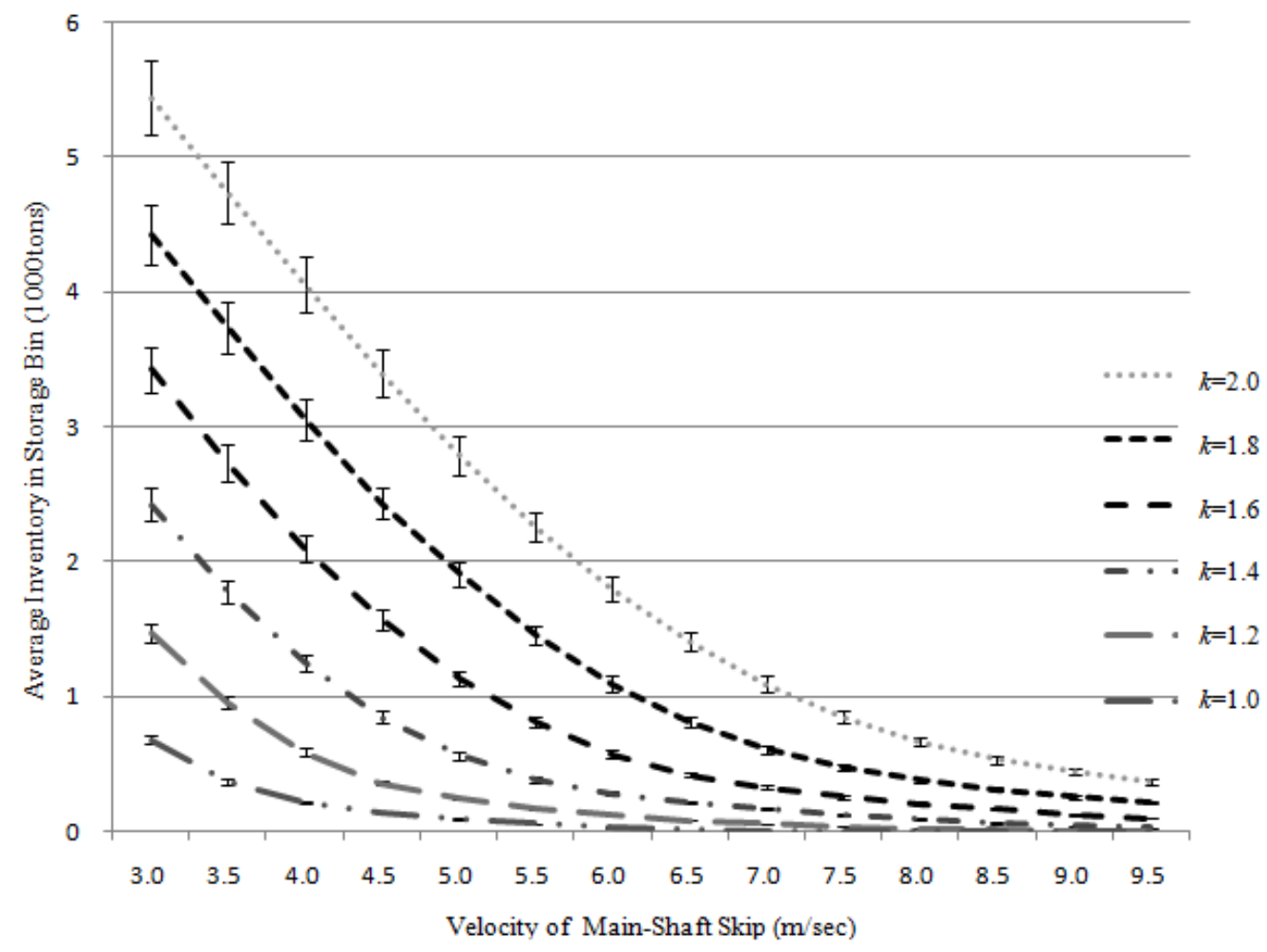

Figure 6: 95\% Confidence interval for average inventory in storage bin 


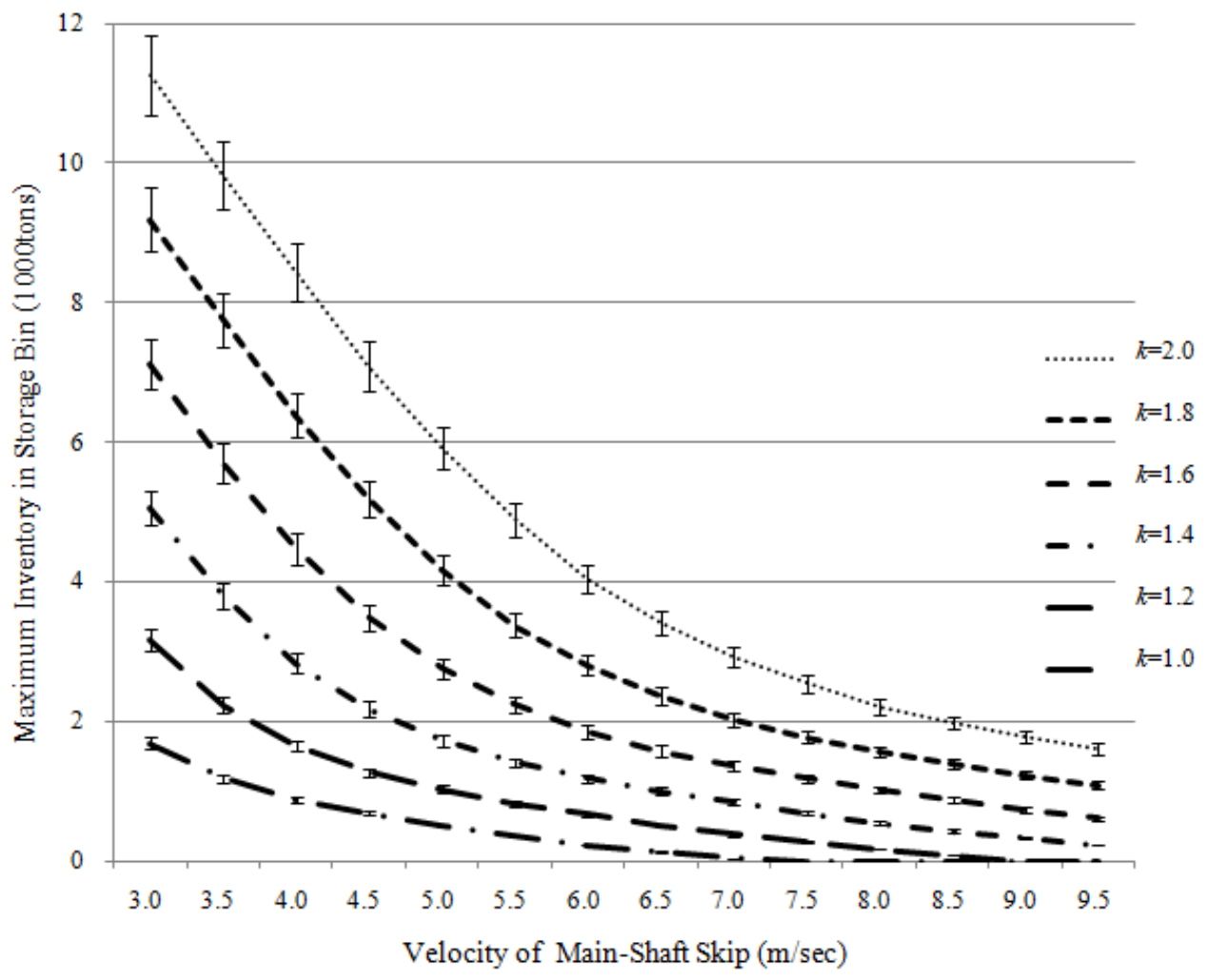

Figure 7: 95\% Confidence Interval for Maximum Inventory in Storage Bin

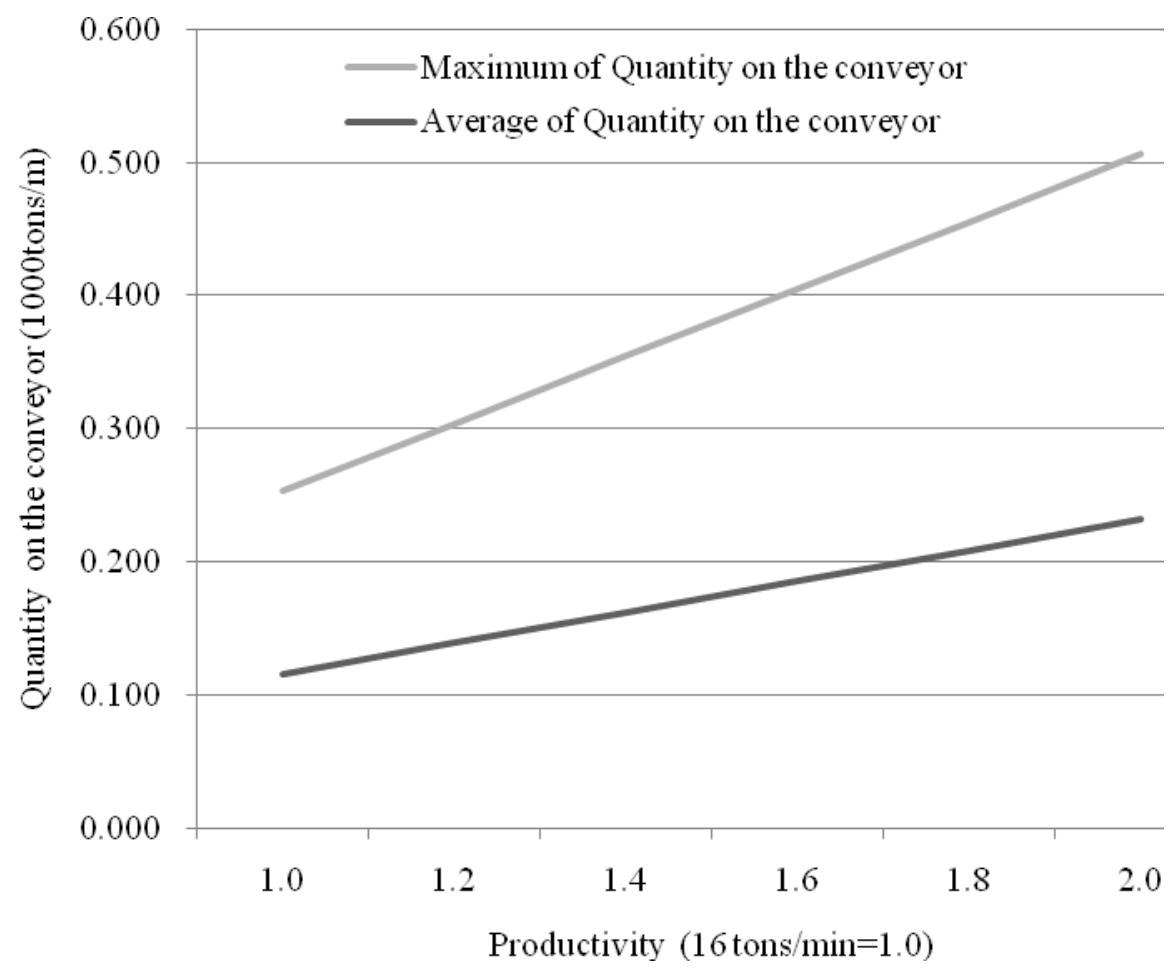

Figure 8: Weight of coal in a unit space on a scraper chain conveyor 


\section{Miwa and Takakuwa}

\section{CONCLUSIONS}

A simulation model of an operations and materials handling system of an underground coal mine was constructed, and a series of experiments were executed. The relationship between the coal output and the materials handling systems was clarified by performing a series of experiments with a simulation model. The amount of coal output was restricted by the conveyance capacity of the main-shaft skips. The required buffer space of the storage bin was determined by the specifications of the materials handling systems and the operating conditions of the longwall shearers at the working face underground. In addition, the required load weight of the conveyors along the dip and the main entry was identified through the simulation experiments. Final decisions should be made by taking safety management into consideration. Although it can be quite difficult to describe model operations and conveyance systems precisely for underground coal mines, it was possible to find the bottleneck of the conveyance system and to determine more efficient mining and conveyance methods by performing simulation.

\section{ACKNOWLEDGMENTS}

The authors wish to express sincere gratitude to Prof. Z. Li and Dr. T. Liu of Beijing Institute of Technology for their cooperation in performing this research. Special thanks should be expressed to Mr. H. Furukawa of Japan Coal Energy Center for his advice on coal mining technology. This research was supported by Grant-in-Aid for Asian CORE Program "Manufacturing and Environmental Management in East Asia" and Grant-in-Aid for Scientific Research of Japan Society for the Promotion of Science (JSPS).

\section{REFERENCES}

Boland, N., I. Dumitrescu, G. Froyland, and A. M. Gleixner. 2009. "LP-based Disaggregation Approaches to Solving the Open Pit Mining Production Scheduling Problem with Block Processing Selectivity." Computers \& Operations Research 36:1064-1089.

Chinbat, U., and S. Takakuwa. 2008. "Using Operation Process Simulation for a Six Sigma Project of Mining and Iron Production Factory." In Proceedings of the 2008 Winter Simulation Conference, edited by S. J. Mason, R. R. Hill, L. Mönch, O. Rose, T. Jefferson, and J.W.Fowler, 2431-2438. Piscataway, New Jersey: Institute of Electrical and Electronics Engineers, Inc.

Coyle, R. 1985. "Representing Discrete Events in System Dynamics Models: A Theoretical Application to Modelling Coal Production." The Journal of the Operational Research Society 36 (4):307-318.

Harper, N., and B. Harper. 1998. "Use of Simulation to Support Mining Industry Operators." In Proceedings of Underground Coal Operators' Conference, edited by N. Aziz, 64-70. University of Wollongong \& the Australasian Institute of Mining and Metallurgy.

Hoare, R. T., and R. J. Willis. 1992. "A Case Study of Animated Computer Simulation in the Australian Mining Industry." The Journal of the Operational Research Society 43(12) :1113-1120.

Japan Coal Energy Center. 2010. Introduction to Coal Exploitation, Part II. Tokyo: Japan Coal Energy Center (in Japanese).

Kazakidis, V. N., and M. Scoble. 2003. "Planning for Flexibility in Underground Mine Production Systems. Mining Engineering." Accessed March 31, 2011. http://www.highbeam.com/doc/1P3404117771.html.

Kelton, D., R. Sadowski, and N. B. Swets. 2010. Simulation with Arena. 5th Edition. New York: McGraw Hill, Inc.

Larinkari, M., J. Kaartinen, and J. Miettunen. 2004. "Modeling and Simulation of Particle Size Distribution in a Mining Process". Accessed March 31, 2011. http://www.simserv.com/white_paper.php?i=0\&ids_string=94.

Profozich, D. 1998. Managing Change with Business Process Simulation. New Jersey: Prentice Hall PRT. 
Stothard, P. M. J. M.Galvin, and J. C. W. Fowler. 2004. "Development, Demonstration and Implementation of a Virtual Reality Simulation Capability for Coal Mining Operations." In Proceedings ICCR Conference. Beijing, China. Accessed March 2011. http://www.mining.unsw.edu.au/Publications/publi staffpubli.htm.

Zhao, D., J. Lucas, and W. Thabet. 2009. "Using Virtual Environments to Support Electrical Safety Awareness in Construction." In Proceedings of the 2009 Winter Simulation Conference, edited by M.D.Rossetti, R.R.Hill, B.Johansson, A. Dunkin and R.G.Ingalls, 2679-2690. Piscataway, New Jersey: Institute of Electrical and Electronics Engineers, Inc.

Zhou, K., and M. Guo. 2011. "Virtual Reality Simulation System for Underground Mining Project". VIRTUAL REALITY, edited by Jae-Jin Kim. Croatia: InTech. Accessed March 31, 2011. http://www.intechopen.com/.

\section{AUTHOR BIOGRAPHIES}

KANNA MIWA is an Associate Professor in the School of Commerce at the Nagoya Gakuin University in Japan. She received her B. Sc. and M. Sc. degrees in Economics from Nagoya University in 2000 and 2003, respectively. She received her Ph.D. from the Graduate School of Economics and Business Administration at Nagoya University in 2006. Her research interests include optimization of logistics, supply chain, and manufacturing systems. Her email is kmiwa@ngu.ac.jp.

SOEMON TAKAKUWA is a Professor in the Graduate School of Economics and Business Administration at Nagoya University in Japan. He received his B. Sc. and M. Sc. degrees in industrial engineering from Nagoya Institute of Technology in 1975 and from Tokyo Institute of Technology in 1977 respectively. His Ph.D. is in industrial engineering from The Pennsylvania State University. He holds a Doctorate of Economics from Nagoya University. He holds a P.E. in Industrial Engineering. His research interests include optimization of manufacturing and logistics systems, management information system and simulation analysis on these systems including hospitals. He has prepared the Japanese editions of both Introduction to simulation using SIMAN and Simulation with ARENA. He has been serving concurrently as the senior staff of Department of Hospital Management Strategy and Planning at Nagoya University Hospital. His email is takakuwa@soec.nagoya-u.ac.jp. 